\title{
Temperature-dependent changes of the exciton absorption spectra in polar semiconductors
}

\author{
Derevyanchuk O.V., Kramar N.K. and Kramar V.M. \\ Chernivtsi Yuriy Fed'kovych National University, 2 Kotsyubynsky St., 58012 \\ Chernivtsi, Ukraine, e-mail: kramar@itf.cv.ua
}

Received: 20.03.2009

\begin{abstract}
Using the model of dielectric continuum for phonons and effective mass approximation for electrons, the influence of longitudinal optical phonons on the formation of exciton spectra in polar semiconductors is studied with the Green function technique. The calculations are made in frame of the Mott-Vannier model for the exciton in $n$ S-states $(n=1,2$ and 3$)$ for a number of semiconductors of $\mathrm{A}_{2} \mathrm{~B}_{6}$ and $\mathrm{A}_{3} \mathrm{~B}_{5}$ groups. The results confirm that interaction of the exciton with longitudinal optical (LO) phonons manifests itself in shifting of absorption band peaks towards low-energy region. The shift differs for different states and depends on temperature. Unlike the main exciton band $(n=1)$, the changes in the positions and widths of the next bands ( $n=2$ and 3 ) resulted from the interaction with the LO phonons are inessential for all the crystals under analysis.
\end{abstract}

Keywords: exciton, absorption spectrum, semiconductor, exciton-phonon interaction

PACS: $71.35 . \mathrm{Cc}$

UDC:535.34

\section{Introduction}

Exciton spectroscopy is a significant instrument in the areas related to physical phenomena and processes in semiconductor crystals. Studies of exciton spectra may provide useful information, e.g., about crystalline and band structures of semiconductors, stationary states of their electron and phonon systems, interaction of the latter systems and the influence of external factors [1-3].

A lot of experimental and theoretical investigations have been devoted to studies of excitons and their interaction with phonons in semiconductors (the corresponding list of works that seems to be far from completion may be found in [1-7]). In particular, the authors [8-11] have developed a theory describing adequately formation of the exciton spectrum and genesis of exciton-phonon interaction (EPI) in polar semiconductors. These studies have mainly addressed the excitons in their ground states. At the same time, wellseparated spectral lines are observed in the long-wave region of the fundamental absorption band for many crystals $[4,5]$, whose origin is attributed to transitions into upper states of the exciton. As a rule, their energies are defined by a quantum number $n$ according to the Elliott equation:

Ukr. J. Phys. Opt. 2009, V10, №3 


$$
E_{n}=E_{g}-\frac{R_{e x}}{n^{2}}
$$

where $E_{g}$ is the forbidden gap, $R_{e x}=\mu^{2} e^{4} /\left(2 \hbar^{2} \varepsilon^{2}\right)$ the Rydberg constant for the exciton and $\mu=m_{e} m_{h} /\left(m_{e}+m_{h}\right)$ the reduced mass of electron and hole [8]. On the other hand, positions of the exciton peaks are often shifted, when compare with those predicted by Eq. (1), especially for the case of $n=1$ [3-5]. Some authors have considered the reasons for those shifts to be associated with anisotropy of band energy spectrum, the influence of surfaces or strains, deviations from three-dimensional exciton model in super-anisotropic and layered crystals, etc.

In this work we present the results of theoretical studies for temperature dependences of spectral characteristics of the absorption bands formed due to transitions into $n S$ exciton states $(n \leq 3)$. These studies deal with semiconductors of the well-known groups, $\mathrm{A}_{2} \mathrm{~B}_{6}$ and $\mathrm{A}_{3} \mathrm{~B}_{5}$. We have found that the interaction with longitudinal optical (LO) phonons in the low-temperature region manifests itself in a shift of exciton absorption peaks towards longer wavelengths. This might be a reason for violation of the serial regularities mentioned above. We demonstrate that, contrary to the main exciton band $(n=1)$, the changes in the positions and widths of the next bands ( $n=2$ and 3$)$, which appear as a result of interaction with LO phonons, are inessential in the crystals under test.

\section{Formulation of the problem and working model}

Our aim is to determine the character of temperature changes in the absorption bands originated from transitions in the $n S$-states of excitons for the case of semiconductor crystals manifesting weak electron-phonon coupling. Mott-Vannier model of the exciton state appearing as a result of vertical photo-transition of electron from the valence band could be used for those crystals. It is generally known that the frequency dependence of the absorption coefficient caused by such transitions is governed by the function

$$
\alpha(\omega, \vec{k})=\frac{2 \pi\left|D_{\vec{k}}(\omega)\right|^{2} \Gamma(\omega, \vec{k})}{\left[\omega-\omega_{\vec{k}}-\Delta(\omega, \vec{k})\right]^{2}+\Gamma^{2}(\omega, \vec{k})}=2 \pi\left|D_{\vec{k}}(\omega)\right|^{2} S(\omega, \vec{k}),
$$

where $D_{\vec{k}}(\omega)$ is the matrix element of dipole moment of the transition to the state $\vec{k}$ ( $\omega$ being the frequency) and $S(\omega, \vec{k})$ denotes the shape function of the absorption band defined by the real and imaginary parts of the mass operator $M(\omega, \vec{k})=\Delta(\omega, \vec{k})-i \Gamma(\omega, \vec{k})$ (see [2]).

The interaction of LO phonons with the first three bands formed by the excitons in their $S$-states could be considered in the framework of one-phonon approximation. Taking into account a weakness of EPI, it is possible to consider only the interaction linear in the phonon operators. Moreover, when neglecting the EPI of the states from different energy bands of the exciton, one can find the mass operator as a function that depends on the light frequency, the wave vector and the temperature $T$ : 


$$
M(\omega, T)=\frac{1}{N \hbar^{2}} \sum_{n, \vec{q}}\left|F_{n}(\vec{q})\right|^{2}\left[\frac{1+v(T)}{\omega-\omega_{\vec{q}}-\Omega+i \gamma}+\frac{v(T)}{\omega-\omega_{\vec{q}}+\Omega+i \gamma}\right],
$$

where

$$
F_{n}(\vec{q})=\sqrt{\frac{2 \pi h e^{2} \Omega}{V_{0} \varepsilon}} \times \frac{1}{q}\left[I_{n}^{(h)}(\vec{q})-I_{n}^{(e)}(\vec{q})\right]
$$

are the functions of EPI. Here

$$
I_{n}^{(p)}(\vec{q})=\iiint e^{i\left(\vec{q}_{p}, \vec{r}\right)}\left|\varphi_{n}(\vec{r})\right|^{2} d^{3} r
$$

represent Fourier images of the electron $(p=e)$ or hole $(p=h)$ distribution densities in the $n$ states, $\vec{q}$ and $\Omega$ denote respectively the wave vector and the phonon frequency, while $\vec{q}_{e}=m_{h} \vec{q} / m_{e x}$ and $\vec{q}_{h}=m_{e} \vec{q} / m_{e x}$. Finally, $m_{e}, m_{h}$ and $m_{e x}=m_{e}+m_{h}$ mean respectively the electron, hole and the exciton masses and $\gamma$ is the parameter that takes longitudinal relaxation of the exciton into account [2].

Using the wave functions of hydrogen-like system in the $n S$-states $(n=1,2$ and 3) and a standard series expansion in terms of spherical functions

$$
e^{i(\vec{q}, \vec{r})}=\sum_{l=0}^{\infty}(2 l+1) i^{l} j_{l}(q r) P_{l}\left(\cos \theta_{q r}\right)
$$

(with $j_{l}(x)$ being the spherical Bessel's functions and $P_{l}(\cos \theta)$ the Legendre's polynomials of the order $l$, and $\theta_{q r}$ the angle between the vectors $\vec{q}$ and $\vec{r}$ ), we get the analytical representation for the functions given by Eq. (5). As a result of spherical symmetry of the wave functions for the $S$-states, only summands with $l=0$ provide nonzero contribution into integrals (5). Then taking into account that

$$
j_{0}(q r)=\frac{\sin q r}{q r}, P_{0}\left(\cos \theta_{q r}\right)=1,
$$

we obtain

$$
I_{1}^{(p)}(\vec{q})=\left[1+\frac{1}{4} q_{p}^{2} a_{e x}^{2}\right]^{-2}
$$

which coincides with the example given in the work [2], and

$$
\begin{gathered}
I_{2}^{(p)}(\vec{q})=\frac{1-3 q_{p}^{2} a_{e x}^{2}+2 q_{p}^{4} a_{e x}^{4}}{\left(1+q_{p}^{2} a_{e x}^{2}\right)^{4}}, \\
I_{3}^{(p)}(\vec{q})=\frac{1-28\left(3 q_{p} a_{e x} / 2\right)^{2} / 3+24\left(3 q_{p} a_{e x} / 2\right)^{4}-16\left(3 q_{p} a_{e x} / 2\right)^{6}+3\left(3 q_{p} a_{e x} / 2\right)^{8}}{\left[1+\left(3 q_{p} a_{e x} / 2\right)^{2}\right]^{6}} .
\end{gathered}
$$

It is convenient to perform analysis of dispersion dependences of the EPI functions using dimensionless variables $y=q a / \pi$ ( $a$ being the lattice constant). Following this approach, we have obtained the dependences under interest: 


$$
F_{n}(y)=\frac{\sqrt{f_{0} \Omega}}{y}\left[I_{n}^{(h)}(y)-I_{n}^{(e)}(y)\right] .
$$

The energy of transition to the $n S$-states from the lowest exciton level $E_{0}=E_{g}-R_{e x}$ may be accounted for as

$$
\hbar \omega_{n \vec{k}}=E_{g}-\frac{R_{e x}}{n^{2}}+\frac{\hbar^{2} k^{2}}{2 m_{e x}},
$$

where $f_{0}=4 \hbar e^{2} a^{2} /\left(V_{0} \varepsilon\right)$ is the EPI factor. Moreover, all the energy parameters could be expressed in the units of exciton bandwidth $L=\pi^{2} \hbar^{2} /\left(2 m_{e x} a^{2}\right)$. Let us denote $w=(\hbar \omega-$ $\left.E_{0}\right) / L$ and perform integration over $y$ variable in the mass operator (3), instead of summation over $\vec{q}$. Then the real and imaginary parts of the mass operator of the $n$-band excitons interacting with LO-phonons will be as follows:

$$
\Delta_{n}(w, T)=f_{0} \Omega \int_{0}^{1} i_{n}(y)\left(\frac{1+v(T)}{Y_{n-}^{2}(w)-y^{2}}+\frac{v(T)}{Y_{n+}^{2}(w)-y^{2}}\right) d y
$$

and

$$
\Gamma_{n}(w, T)=\Gamma_{n 0}+\frac{\pi f_{0} \Omega}{2}\left(\frac{i_{n}\left[Y_{n-}(w)\right] \cdot[1+v(T)]}{Y_{n-}(w)}+\frac{\left.i_{n}\left[Y_{n+}(w)\right] \cdot v(T)\right]}{Y_{n+}(w)}\right),
$$

where $\Gamma_{n 0}$ is the radiation broadening of the exciton absorption band, $i_{n}(y)=\left[I_{n}^{(h)}(y)-I_{n}^{(e)}(y)\right]^{2}, Y_{ \pm}(w)=\sqrt{w-\left(R_{e x}\left(1-1 / n^{2}\right) \pm \hbar \Omega\right) / L}$ and the integral in Eq. (11) should be calculated in the sense of its principal value.

As a consequence, one can investigate temperature and frequency dependences of the shape function of the absorption band linked with the transition into exciton $n S$-state,

$$
S_{n}(w, T)=\frac{\Gamma_{n}(w, T)}{\left[w-R_{e x}\left(1-1 / n^{2}\right)-\Delta_{n}(w, T)\right]^{2}+\Gamma_{n}^{2}(w, T)},
$$

provided that the real and imaginary parts of the mass operator are known.

\section{Results and discussion}

The calculations have been performed on the example of semiconducting $\mathrm{A}_{2} \mathrm{~B}_{6}$ and $\mathrm{A}_{3} \mathrm{~B}_{5}$ compounds with different EPI powers (see Table 1).The relevant results show the probability of low-energy shift of the absorption bands, which is associated with the transitions into both the ground and the higher exciton states. It is clearly seen that the shift value increases with increasing temperature.

At $T=0 \mathrm{~K}$ the absorption bands corresponding to the transition into the ground exciton state in $\beta-\mathrm{CdS}, \mathrm{CdTe}$ and GaAs crystals are shifted towards the long-wave region approximately by 6,4 and $2 \mathrm{meV}$, respectively (see Fig. 1). Temperature increase leads to increasing shift for the absorption band, broadening of the latter and, thus, decreasing height of the absorption maximum. Due to energy differences among the optical phonons peculiar for the crystals investigated by us the displayed regions of temperature changes 

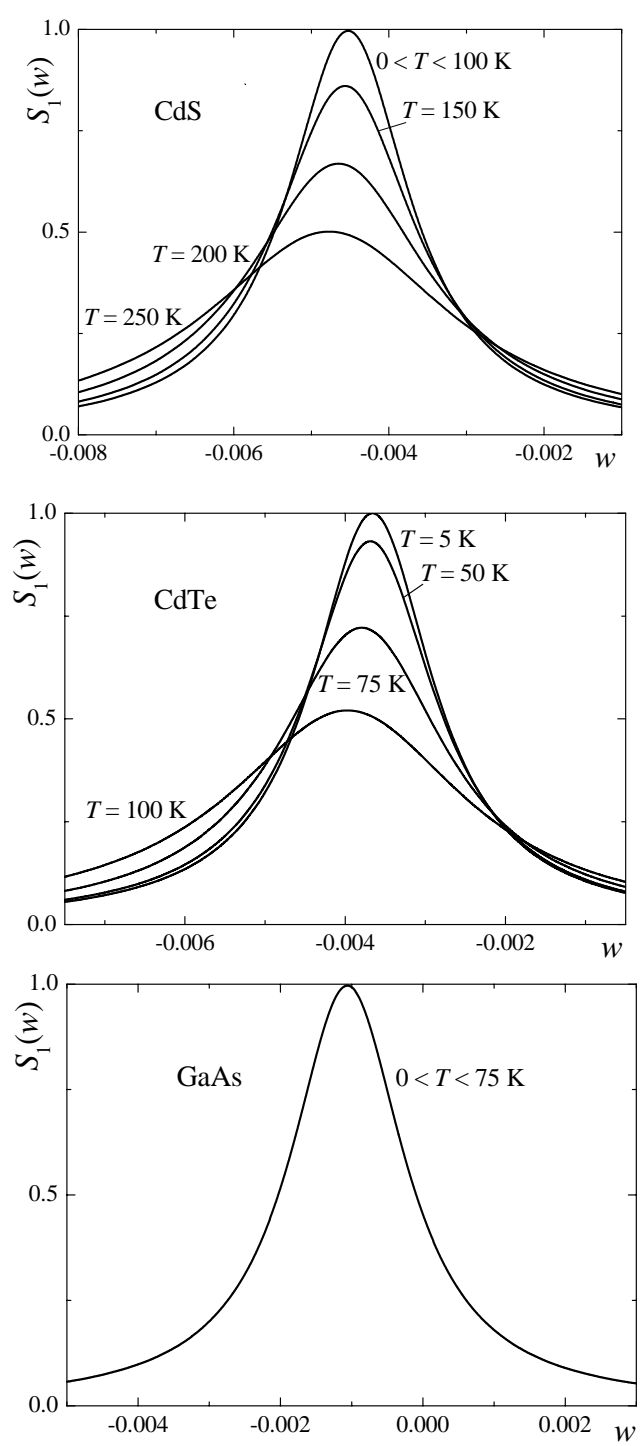

Fig. 1. Shape function $S_{1}(w)$ for the absorption band of exciton transition into $1 S$-state.
Table 1. Some physical parameters of semiconductor compounds under analysis (see explanations in the text)

\begin{tabular}{|c|c|c|c|}
\hline Parameters & $\beta$-CdS & CdTe & GaAs \\
\hline$a, \AA$ & 5.818 & 6.482 & 5.653 \\
\hline$\varepsilon_{0}$ & 9.10 & 10.2 & 13.18 \\
\hline$\varepsilon_{\infty}$ & 5.50 & 7.1 & 10.89 \\
\hline$m_{e} / m_{0}$ & 0.20 & 0.09 & 0.067 \\
\hline$m_{h} / m_{0}$ & 0.70 & 0.72 & 0.62 \\
\hline$\Omega, \mathrm{meV}$ & 57.20 & 21 & 36.25 \\
\hline$E_{g}, \mathrm{eV}$ & 2.5 & 1.61 & 1.424 \\
\hline$R_{e x}, \mathrm{meV}$ & 25.56 & 10.46 & 4.74 \\
\hline$L, \mathrm{eV}$ & 1.24 & 1.11 & 1.72 \\
\hline$f_{0}$ & 0.092 & 0.055 & 0.015 \\
\hline
\end{tabular}

are different. So, the lower temperature limit for CdTe and GaAs is $T \geq 50 \mathrm{~K}$, whereas for $\mathrm{CdS}$ we begin the analysis at $T \geq 100 \mathrm{~K}$. The upper limit is fixed by the term $k_{B} T \leq R_{e x}$ and so it is different, too. This limit is the highest for CdS $(250 \mathrm{~K})$ and the lowest for GaAs $(75 \mathrm{~K})$. This is why the temperature changes in the ground exciton absorption band might be quite expected for $\mathrm{CdS}$, are less probable for CdTe and improbable for GaAs.

The transitions into the $2 S$-state in the crystals under study are characterized as nearly symmetrical bands, which are displaced to the long-wave region by 0.9 (CdS), 0.7 (CdTe) and $0.2 \mathrm{meV}$

(GaAs) at $T=0 \mathrm{~K}$. Temperature increase causes a slightly increased shift (less than $0.1 \mathrm{meV}$ ) of the band maximum towards the long-wave region, though it does not practically alter the bandwidth and the height of the absorption maximum (see Fig. 2). The same occurs with the bands formed by the transitions into $3 S$ states: they are symmetrical and become displaced to the same side, though notably less $(0.18,0.10$ and $0.08 \mathrm{meV}$, respectively). The location, width and the height of the absorption peak referred to the exciton transition to $3 S$-state are practically independent of temperature (Fig. 3).

Assuming that the oscillator strengths for the exciton transition are proportional to $n^{3}$ [5], one can represent the exciton absorption spectrum using a scheme shown in Fig. 4. 

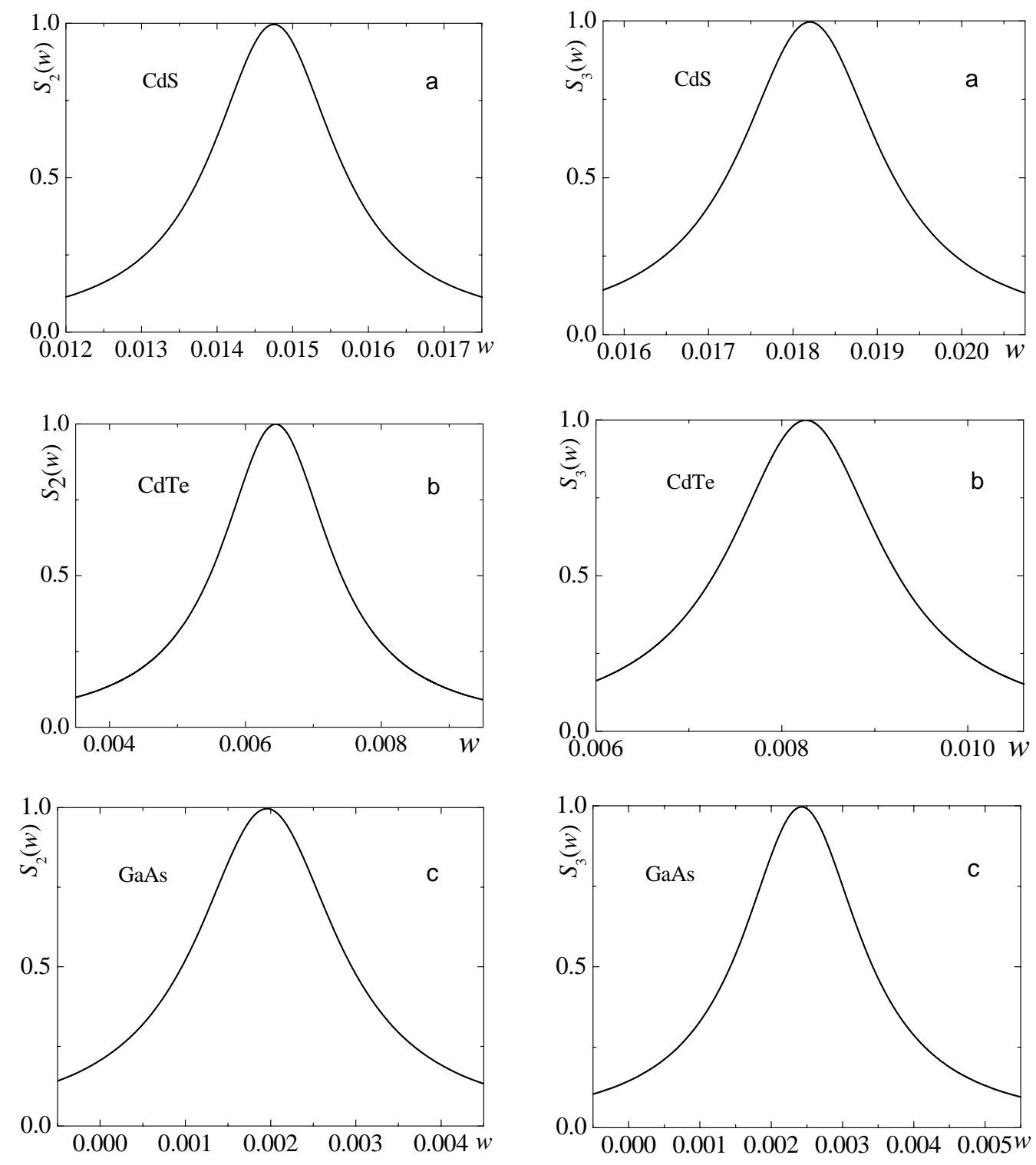

Fig. 2. Shape function $S_{2}(w)$ for the absorption band of exciton transition into $2 S$-state

Fig. 3. Shape function $S_{3}(w)$ for the absorption band of exciton transition into 3S-state

Hence, the factor $f_{0}$ and the bands' shifts and halfwidths decrease for our compounds arranged according to the EPI value (see Table 1). All the bands for $\beta$-CdS are narrow and well spaced out. The bands $n=2$ and $n=3$ for CdTe are placed one by one and form a wide band of a well-structured shape, while in GaAs such the structure disappears. Thus, separate observation of the absorption bands corresponding to $n=2$ and $n=3$ is hardly possible for all polar semiconductors. It is explained by difference of parameters for those crystals: the efficient Rydberg constant of the exciton, the phonon energy and the EPI factor. 

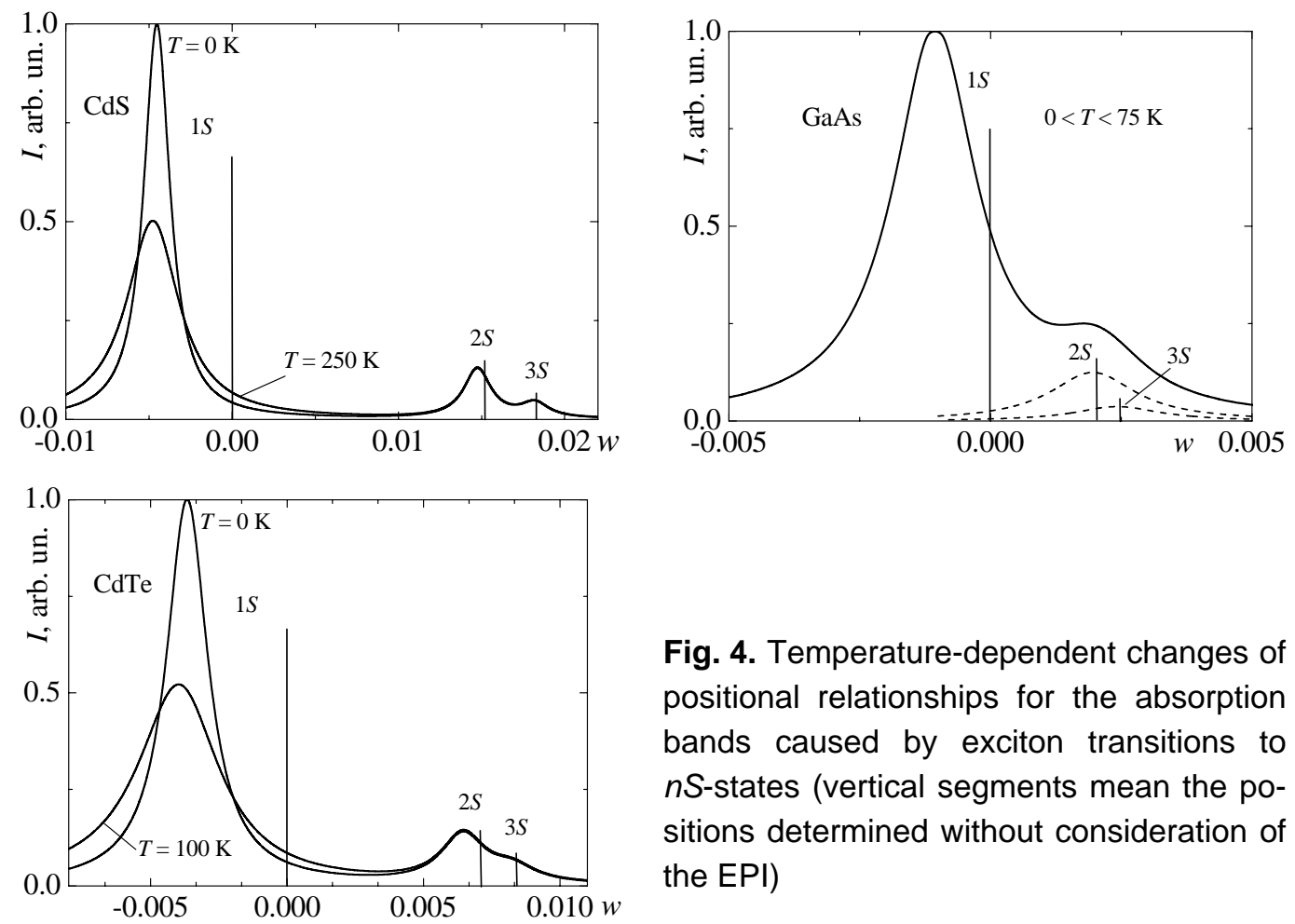

Fig. 4. Temperature-dependent changes of positional relationships for the absorption bands caused by exciton transitions to $n S$-states (vertical segments mean the positions determined without consideration of the EPI)

The differences of wave numbers $\left(k_{2}-k_{1}\right),\left(k_{3}-k_{1}\right)$ and $\left(k_{3}-k_{2}\right)$ computed in this way for the transitions mentioned above exceed those calculated with Eq. (1) for all the crystals under test: the corresponding ratios are equal to $1.244,1.237$ and 1.2 for $\beta$-CdS, $1.44,1.43$ and 1.373 for $\mathrm{CdTe}$, and $1.50,1.43$ and 1.046 for GaAs. The ratio $\left(k_{2}-k_{1}\right) /\left(k_{3}-k_{1}\right)$ is also lager than that calculated with Eq. (1) by factor of 1.005 ( $\beta$-CdS), $1.007(\mathrm{CdTe})$ and $1.046(\mathrm{GaAs})$. The values reported here somewhat exceed those determined from the exciton spectrum of $\operatorname{CdS}(1.12,1.099,0.994$ and 1.02, respectively see [4]).

This can be explained by drawbacks of the models, which take into account only a single mechanism for the exciton relaxation (namely, interaction with the optical phonons), or by discrepancy parameters chosen for the calculations (in the work [4] a polytype of the crystal has not been specified). However, the results obtained in frame of our models prove a possibility for the violation of serial regularities and reveal a difference among the EPI efficiencies for different $n S$-states.

\section{Conclusions}

On the basis of results of our calculations we can state the following:

(i) The EPI can be the reason for deviation from the serial regularity of exciton absorption bands, which has been earlier confirmed experimentally. The effect of the EPI should increase with increasing temperature.

(ii) The efficiency of EPI differs for different $n S$-states. This is explained by different character of the EPI functions depending on the wave vector. As a result, the shift value and the band broadening in various crystals depend not only on the EPI factor $f_{0}$, 
but also on the exciton binding energy of the corresponding state.

(iii) Broadening of the exciton absorption bands formed by transitions to the excited states is very small, irrespective of the temperature.

\section{References}

1. Excitons. Eds. Rashba E. and Struge M. Moscow: Nauka (1985).

2. Davydov A. Theory of the solid state. Moscow: Nauka (1976).

3. Brodin $\mathrm{M}$ and Blonskii I, Excitonic processes in layered crystals. Kiev: Naukova dumka (1986).

4. Gross E, 1962. Exciton and its motion in the crystal lattice. Usp. Fiz. Nauk 76: 433-442.

5. Fan H, Photon-electron interaction. Crystals without fields. New-York: SpringerVerlag (1967).

6. Zhirko Yu, 1999. Investigation of the light absorption mechanisms near exciton resonance in layered crystals. Part 2. N = 1 state exciton absorption in GaSe. Phys. stat. sol. (b) 213: 93-106.

7. Zhirko $\mathrm{Yu}, 2000$. Investigation of the light absorption mechanisms near exciton resonance in layered crystals. $\mathrm{N}=1$ state exciton absorption in InSe. Phys. stat. sol. (b) 219: 47-61.

8. Elliott R, 1957. Intensity of optical absorption by excitons. Phys. Rev. 108: $1384-1389$.

9. Lubchenko A, Nitsovich V and Tkach N, 1974. Dispersion of dielectric permeability tensor for polar semiconductors in the exciton absorption region. Zhurn Teor. Mat Fiz. 21: $415-423$.

10.Tkach N, Nitsovich V and Voronyak Ya, 1974. Temperature dependence of exciton peak position in the framework of extended model of exciton-phonon system. Ukr. Fiz. Zh. 24: 58-73.

11.Nitsovich B, 1986. Electron-phonon interaction in the layer semiconductors. Fiz. Tv. Tela 28: 2424-2427.

12.Zhirko Yu and Zharkov I, 2002. Light absorption by excited exciton states in layered InSe crystals. Semiconductor Physics, Quantum Electronics \& Optoelecrtonics 5: $156-162$.

Derevyanchuk O.V., Kramar N.K. and Kramar V.M., 2009. Temperature-dependent changes of the exciton absorption spectra in polar semiconductors. Ukr.J.Phys.Opt. 10: 157-164.

Анотація Використовуючи модель діелектричного континууму для фононів і наближення ефективної маси для електронів, методом функиій Гріна досліджено вплив повздовжніх оптичних фононів на формування екситонного спектра в полярних напівпровідниках. Розрахунки проведено в рамках моделі Ваньє-Мотта для екситонів в $n S$-станах $(n=1,2,3)$ для напівпровідників $A_{2} B_{6}$ та $A_{3} B_{5}$ - груп. Результати підтверджують, що взаємодія екситону 3 повздовжніми оптичними (LO) фононами проявляється у зміщенні смуги поглинання 6 область низьких енергій. Це змішення відрізнясться для різних станів і залежить від температури. На противагу основній екситонній смузі $(n=1)$, зміна положення $і$ ширини наступних смуг ( $n=2$ та 3) викликана взаємодією з LO фононами є несуттєвою для всіх проаналізованих кристалів. 